\title{
Prospective K-8 teachers' noticing of student justifications and generalizations in the context of analyzing written artifacts and video-records
}

\author{
Marta T. Magiera ${ }^{{ }^{*}}$ (D) and Vecihi S. Zambak²
}

\begin{abstract}
Background: This paper contributes to current discussions about supporting prospective teachers (PSTs) in developing skills of noticing students' mathematical thinking. We draw attention to PSTs' initial noticing skills (prior to instruction focused on supporting noticing) as PSTs engage in analyzing written artifacts of student work and video-records. We examined and compared PSTs' noticing skills as they analyzed how students reason about, generalize, and justify generalizations of figural patterns given student written work and video records. We identified aspects of student thinking about generalizations and justifications, which PSTs addressed and interpreted. We also examined how PSTs respond to students as they analyze student thinking given written artifacts of student work or video-records of small group discussions, and we identified the foci of PSTs' responding practice.

Results: Our data revealed that PSTs' initial noticing skills of student generalizations and justifications differed while accounting for ways in which student thinking was externalized (written work or video-records). PSTs' attendingand-interpreting and their responding practices were focused on mathematically significant aspects of student thinking to a greater extent in the context of analyzing written artifacts compared to video records. While analyzing students' written work, PSTs demonstrated greater attention to ways in which students analyzed patterns, students' generalization strategies, and justifications linked to an understanding of the pattern structure, compared to analyzing student thinking captured via videos.

(Continued on next page)
\end{abstract}

\footnotetext{
* Correspondence: marta.magiera@marquette.edu

${ }^{1}$ Department of Mathematical and Statistical Sciences, Marquette University,

P.O. Box 1881, 1313 W. Wisconsin Avenue, Milwaukee, WI 53201-1881, USA

Full list of author information is available at the end of the article
}

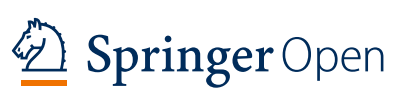

(c) The Author(s). 2021 Open Access This article is licensed under a Creative Commons Attribution 4.0 International License, which permits use, sharing, adaptation, distribution and reproduction in any medium or format, as long as you give appropriate credit to the original author(s) and the source, provide a link to the Creative Commons licence, and indicate if changes were made. The images or other third party material in this article are included in the article's Creative Commons licence, unless indicated otherwise in a credit line to the material. If material is not included in the article's Creative Commons licence and your intended use is not permitted by statutory regulation or exceeds the permitted use, you will need to obtain permission directly from the copyright holder. To view a copy of this licence, visit http://creativecommons.org/licenses/by/4.0/. 
(Continued from previous page)

Conclusion: Our results document that without providing any intentional support for PSTs' noticing skills, PSTs are more deliberate to focus on mathematically significant aspects of student thinking while analyzing written artifacts of student work compared to video-records. We believe that the analysis of student written work might demand from PSTs to be more analytical. While examining written representations, PSTs have to reconstruct students' reasoning. Unlike the videos where the students tell or use gestures to express their thinking, written work provides fewer clues about student thinking. Thus, written work demands a deeper level of engagement from PSTs as they strive to understand student reasoning. Our study extends research on PSTs' noticing skills by documenting differences in PSTs' noticing in relation to the nature of artifacts of student work that PSTs analyze. Our work also adds to prior research on PSTs' noticing by characterizing specific aspects of students' thinking about pattern generalizations and justifications that PSTs address as they analyze student thinking and respond to students.

Keywords: Professional noticing, Prospective K-8 teacher education, Justification, Pattern generalization

\section{Introduction}

Research on teacher development motivates attention to teacher noticing in preparation of mathematics teachers (e.g., Goldsmith \& Seago, 2011; Jacobs, Lamb, \& Philipp, 2010; Jacobs, Lamb, Philipp, \& Schappelle, 2011; Mason, 2002; Sherin \& van Es, 2009; Star \& Strickland, 2008; van Es \& Sherin, 2002) and science teachers (e.g., Barnhart \& van Es, 2015; Luna, 2018; Luna, Selmer, \& Rye, 2018). Teachers who notice student thinking, that is, identify and make sense of students' mathematical and scientific ideas and build on these ideas appropriately while making pedagogical decisions, are positioned to support reformoriented, student-centered mathematics and science instruction. The ability to notice and make sense of student thinking and to use these observations to respond to students is closely related to teacher effectiveness in the classroom (e.g., Carpenter, Fennema, Peterson, Chiang, \& Loef, 1989; Chamberlin, 2005; Crespo, 2000; Kleinknecht \& Gröschner, 2016; Mason, 2002; Prediger \& Zindel, 2017; Sun \& van Es, 2015). Professional noticing, a complex and challenging teaching practice, needs then to be developed in teacher education programs (e.g., Jacobs et al., 2010; Santagata, Zannoni, \& Stigler, 2007; Sherin \& Han, 2004; Sherin \& van Es, 2005, 2009; Star \& Strickland, 2008; van Es, 2011; van Es \& Sherin, 2002).

The attention to noticing skills in preparation of prospective teachers (PSTs) is also important from the perspective of teacher educators. PSTs' noticing skills provide a window into understanding how PSTs make sense of students' thinking or complex classroom situations (Barnhart \& van Es, 2015; Sherin, Jacobs, \& Philipp, 2011; Simpson \& Haltiwanger, 2017; Zambak \& Magiera, 2018). Such understanding positions teacher educators to be more effective in preparing PSTs to understand the complexities of mathematics and science learning and teaching.

In this paper, we explore elementary and middle grades PSTs' initial professional noticing of student mathematical thinking (i.e., prior to explicit instruction supporting PSTs' noticing skills) with attention to their noticing of students' thinking about pattern generalizations and justifications. Our work extends the existing body of research on teacher noticing by examining and comparing PSTs' noticing skills as they analyze students' written work and video-records in which students share their reasoning in small groups. We focus on students' written work and video-records because these modes of presenting student thinking are frequently used across studies on teacher noticing. Explicit focus on student generalizations and justifications also uniquely distinguishes our study from prior work on teacher noticing. Our study answers the following research questions:

1. How might PSTs' initial noticing of student thinking related to pattern generalizations and justifications differ between video-records and written artifacts of student work?

2. What do PSTs notice while analyzing student thinking about pattern generalizations and justifications given video-records or written artifacts of student work?

\section{Conceptual foundations and review of the related literature}

The practice of teacher noticing

Researchers have proposed several frameworks for thinking about and operationalizing the practice of teacher noticing (e.g., Jacobs et al., 2010, 2011; Llinares, 2013; Mason, 2002; Philipp, Fredenberg, \& Hawthorn, 2017; Sherin \& Han, 2004; van Es, 2011). Common across the various conceptualizations of teacher noticing is the notion of intentional noticing, that is, the ability to identify important classroom events, connect them to teaching situations, and broader concepts related to teaching and student learning. One specific aspect of teacher noticing is the ability to notice students' mathematical thinking. Llinares (2013) argued that noticing students' mathematical thinking goes beyond the mere recognition of the 
correctness of students' responses. Teachers who notice students' mathematical thinking are able to recognize whether or not students' approaches and reasoning are meaningful. Jacobs et al. (2010) described Professional Noticing of Students' Mathematical Thinking in terms of three connected practices: (1) attending to mathematical details in students' thinking and strategies, (2) interpreting students' mathematical understanding and reasoning with a focus on details of the specific strategies, and (3) deciding how to respond to students in a way that builds on students' thinking, understanding, and strategies. Philipp et al. (2017) described that these noticing practices are "highly interrelated and often occur seemingly simultaneously" (Philipp et al., 2017, p. 114). Bautista, Brizuela, Glennie, and Caddle (2014) noted that attending to and interpreting student thinking are often inseparable. They argued that teachers tend to attend to a specific aspect of student thinking and simultaneously interpret it as they prepare their response. Consequently, in our work with PSTs, we view Professional Noticing of Students' Mathematical Thinking (hereafter Professional Noticing) in terms of two, rather than three practices: Attending-and-Interpreting mathematically significant aspects of student thinking, and deciding how to respond to students in a way that connects to their mathematical thinking, i.e., Responding.

\section{Research on PSTs' noticing skills}

Researchers recognize that PSTs need support in learning to notice students' thinking. They also acknowledge that for many PSTs identifying students' mathematical ideas is challenging (e.g., Stockero, Rupnow, \& Pascoe, 2017; Teuscher, Leatham, \& Peterson, 2017). Seeking an understanding of ways to support PSTs in developing professional noticing skills has attracted increased interest in mathematics education research. At the same time, research on teacher noticing raises several questions about comparing the effectiveness of different interventions designed to support teachers (including PSTs) in developing their noticing skills.

First, past research has not been grounded in a strong understanding of the relationship between the nature of representations of practice used to capture student thinking or ways in which PSTs externalize what they notice, and the assessment of PSTs' noticing skills. Some researchers engaged PSTs in analyzing student thinking using only written artifacts of student work (e.g., Fernández, Llinares, \& Valls, 2013; Simpson \& Haltiwanger, 2017). Other researchers used only video-records of small groups or class discussions to support and examine teachers' noticing skills (Krupa, Huey, Lesseig, Casey, \& Monson, 2017; Star \& Strickland, 2008; van Es, 2011; van Es \& Sherin, 2008). However, Goldsmith and Seago (2011) and Superfine and Bragelman (2018) documented that what teachers notice and how they make sense of student mathematical thinking might be mediated by the nature of representations used to capture student thinking.

For example, Superfine and Bragelman (2018) tested the impact of videos with varying degrees of complexity on PSTs' learning to notice student mathematical thinking. They reported that videos of small groups in which students worked on tasks that evoked multiple solution strategies were more effective than videos that captured individual students' thinking. Videos in which teachers did not interact with groups were also more effective in supporting PSTs' noticing skills than videos in which teachers interacted with students by guiding and scaffolding their mathematical activity. Goldsmith and Seago (2011) shared similar observations about representations used to support practicing teachers' noticing. They studied two professional development programs: one in which teachers analyzed written artifacts of students' work and one in which teachers analyzed videorecords for evidence of students' algebraic thinking. Teachers who examined written work showed significantly greater attention to mathematics in students' solutions and strategies and less likely commented on non-mathematical aspects of students' work compared to the teachers who examined video-records.

Moreover, research has also documented that the assessment of teacher noticing skills might relate to ways in which teachers articulate what they notice and express their understanding of students' mathematical thinking. Across the research on teacher noticing, researchers utilize a broad range of strategies to gain access to teacher noticing skills. Some researchers relied on PSTs' written analyses of student thinking (e.g., Callejo \& Zapatera, 2017; Fernández et al., 2013; Zambak \& Magiera, 2018). Others conducted oral interviews with PSTs to document what PSTs noticed as they analyzed student mathematical activity (e.g., Schack et al., 2013; van den Kieboom, Magiera, \& Moyer, 2017). Researchers also accessed teachers' noticing skills using group discussions in which teachers collectively shared their observations of student thinking (e.g., González \& Skultety, 2018; Jilk, 2016). A study by Amador, Estapa, de Araujo, Kosko, and Weston (2017) showed that how PSTs articulate their observations of student thinking might affect the assessment of PSTs' noticing skills. Amador and colleagues presented PSTs with two video clips of elementary school students who reasoned about division of fractions. They asked PSTs to share their observations in writing and via scripted animations that PSTs designed to depict their observations. Amador et al. reported vast differences in PSTs' noticing skills while accounting for ways in which PSTs communicated what they noticed. When articulating their noticing in writing, 
PSTs predominantly made observations about students, but when using animations to say what they noticed, PSTs focused mostly on a teacher. At the same time, those PSTs who expressed their noticing about students did so with greater attention to mathematical details in their animations compared to written responses. The study of Amador et al. (2017) shows that how individuals communicate what they notice might also impact the overall assessment of noticing skills. Together, these studies raise a question about PSTs' noticing skills when PSTs examine different ways in which student thinking is captured (e.g., video-records, students' written work) but consistently express their noticing using the same mode (e.g., in writing).

Finally, past studies on teacher professional noticing do not always illuminate content-specific mathematical ideas that teachers notice (e.g., Callejo \& Zapatera, 2017; Fernández et al., 2013; Lee, 2018; Lee \& Choy, 2017; Star \& Strickland, 2008; van Es, 2011). For example, van Es (2011) characterized teacher noticing skills broadly in the context of classroom instruction. She delineated what teachers notice and how they notice as they focus on student thinking on a continuum from Level 1, Baseline, to Level 4, Extended. Level 1 noticing represented a teacher's ability to attend to a whole class environment, student learning, and pedagogy, and Level 4 noticing represented attending to the relationship between students' mathematical thinking and teaching strategies. Others (e.g., Callejo \& Zapatera, 2017; Lee, 2018; Lee \& Choy, 2017) provided similar broad descriptions of noticing skills working with PSTs. For example, Callejo and Zapatera (2017) studied PSTs' noticing of elementary school students' understanding of pattern generalization. The five profile levels of PSTs' noticing they described provided information about the number of specific characteristics of student understanding and mathematical features that PSTs addressed. In the context of analyzing records of mathematics class instruction, Star and Strickland (2008) discussed PSTs' noticing of the classroom environment, classroom management, communication, mathematics tasks, and mathematics content (broadly described). While these research-based trajectories provide useful guides for mathematics teacher educators and tools for assessing PSTs' noticing skills, they offer limited information about content-specific mathematical ideas PSTs notice.

Philipp et al. (2017) argued that helping PSTs develop the practice of noticing student mathematical thinking requires knowledge of mathematical ideas that PSTs notice while analyzing student thinking in well-defined content domains. In this paper, we focus on PSTs' noticing of student pattern generalization and justifications. Generalizing and justifying general statements has been frequently linked to algebraic reasoning and, as such, holds a special place in the elementary and middle school mathematics curriculum (e.g., Blanton \& Kaput, 2000; Lee, 1996; Mason, 1996; Radford, 2008). Below, we describe both terms to highlight the mathematical content focus of our study.

\section{Generalizing and justifying}

In the mathematics education literature, generalizing and justifying are often defined in terms of processes or products (Yerushalmy, 1993). The view of generalizing as a process emphasizes activities in which students engage to extend their reasoning beyond the initial set of cases to derive a broader result. Such activities, for example, include drawing stages of a pattern and counting, identifying invariant, and changing pattern characteristics, composing, or decomposing pattern structure (e.g., Amit \& Neria, 2008; Becker \& Rivera, 2005; Ellis, 2007a, 2007b; Lannin, 2005; Lannin, Barker, \& Townsend, 2006; Radford, 2008; Rivera, 2018). The view of generalizing as a product emphasizes outcomes of the processes in which students engage. For example, generalizations resulting from analyzing non-overlapping parts in the structure of the pattern are described as constructive. Those resulting from analyzing overlapping parts in the pattern structure and reasoning about them to describe properties of all cases are described as deconstructive (e.g., English \& Warren, 1998; Rivera \& Becker, 2009). Generalizations are also described as transformative, i.e., resulting from reorganizing pattern structure (e.g., Rivera, 2010), or recursive, i.e., resulting from analyzing discrete parts in the pattern and "finding the $n+1$ term given the $n$th term" (Krebs, 2005, p. 285). We used these descriptions of generalizations as a guide for our work with PSTs.

Justifications constitute an inherent aspect of generalizations and are interpreted as arguments that provide insights into why the generalization is valid for all cases (e.g., Rivera \& Becker, 2009). When supporting general claims, one draws on established ideas, definitions, properties, or already accepted as true general statements. Researchers document different schemes that characterize student justifications of figural patterns (e.g., Lannin, 2005; Rivera \& Becker, 2007). Researchers also show that despite the curricular emphasis on constructing and justifying general mathematical claims, justifying is difficult for many students (e.g., Ellis, 2007b; Knuth, Choppin, Slaughter, \& Sutherland, 2002; Lannin, 2005; Russel, Schifter, \& Bastable, 2011). After finding a few examples that support the claim, students often conclude that a specific mathematical result is valid for all instances. Thus, they use perceptual scheme testing the general rules with examples and appealing to physical facts or sensory experiences. Students who recognize the limitations of empirical justifications draw on their 
understanding of pattern structure persuading general statements' validity.

\section{Teachers' noticing of student generalizations and justifications}

To date, only a few studies directly addressed practicing teachers' noticing of student generalizations and justifications (e.g., LaRochelle et al., 2019; Melhuish, Thanheiser, Fasteen, \& Fredericks, 2015; Melhuish, Thanheiser, \& Guyot, 2020; Mouhayar \& Jurdak, 2013). Studies that explored PSTs' noticing of student generalizations and justifications are even more scarce (e.g., Callejo \& Zapatera, 2017). These studies describe teachers' difficulties in either identifying student generalization or justification strategies, making sense of student strategies, or both. For example, LaRochelle et al. (2019) reported that secondary school mathematics teachers recognized strategies students used to generalize a pattern and identified the connections between students' symbolic rules and pattern structure. They, however, did not interpret student understanding meaningfully. Mouhayar and Jurdak (2013) documented that teachers did not explain how students developed symbolic (algebraic) rules and justified general rules, even though they identified strategies students used to extend given patterns. Many teachers in Melhuish et al.'s (2020) study relied on surface clues while interpreting student generalizations and justifications without making in-depth observations of student thinking. None of these studies explored PSTs' noticing skills of student generalizations and justifications with attention to different ways in which student thinking was captured (e.g., written work, video-records).

\section{Methods}

\section{Participants and study context}

Data for this research come from a project conducted at a Midwestern University in the USA. The project investigated PSTs' learning about mathematical argumentation, justification, and proof in elementary and middle grades mathematics classrooms, in the context of their mathematics coursework in their teacher preparation program. Featured in this paper are 15 PSTs enrolled in the same section of a semester-long mathematics course, Algebra and Geometry for Teachers. Participants were undergraduate elementary education majors. All but one were at the beginning of their 3rd year at the University. At the time of the study, all participants completed two mathematics courses in their teacher preparation program but were not previously engaged in analyzing student thinking about generalizations and justifications. All PSTs enrolled in the course were invited to participate, and all volunteered their participation and provided consent. Consistent with our Institutional Review Board
(IRB) protocol, we did not engage in an in-depth analysis of the PSTs' data until after completing the course.

The course that provided context for our study was the last in a three-course mathematics content course sequence for elementary education majors. The course had three broad objectives: (1) to support PSTs' conceptual understanding of algebra and geometry related ideas essential to elementary and middle school mathematics curriculum, (2) to support PSTs' understanding of generalization and justification as mathematical practices of making conjectures, and (3) to support their understanding of student mathematical thinking. The instructional emphasis was placed on mathematical reasoning, justifying mathematical ideas and procedures, constructing, interpreting, and assessing the quality of mathematical arguments. The class met twice a week for $75 \mathrm{~min}$. Our goal was to heighten PSTs' awareness of different ways of thinking and generalization strategies. Class activities included discussions of recursive or explicit thinking and were designed to support PSTs' knowledge and deepen their conceptions of valid mathematical justifications and build their understanding of student mathematical thinking in the context of analyzing and generalizing patterns. In our work with PSTs, we discussed generalizations as both the process and the product (see the Generalizing and justifying section). We focused on PSTs' initial noticing skills. For that reason, we did not explicitly engage PSTs in discussions about the noticing practice, reading the relevant literature on teacher noticing, or rehearsal activities (i.e., modeling of attending-and-interpreting, and responding practices). We also did not analyze the data until PSTs responded to all tasks. In Fig. 1, we summarize the instructional sequence that provided the context for this study.

\section{Data sources and data collection}

Data were collected during the first part of the semester, during which PSTs studied topics related to elementary and middle school algebra and algebraic thinking. During this unit of study (see Fig. 1), PSTs investigated various numerical and figural patterns, formulated conjectures about them, and engaged in developing and justifying recursive and explicit rules. PSTs discussed activities and strategies that support generalizing patterns and reflected on the validity of provided justifications in the context of their own mathematical work and analyses of student work they conducted.

To understand what strategies and ways of thinking exhibited by students making generalizations and justifications PSTs notice, we designed and implemented two sets of parallel tasks. We also designed these tasks to understand the role of context in which PSTs examine students' mathematical thinking. In each task, we engaged PSTs in analyzing students' reasoning about 


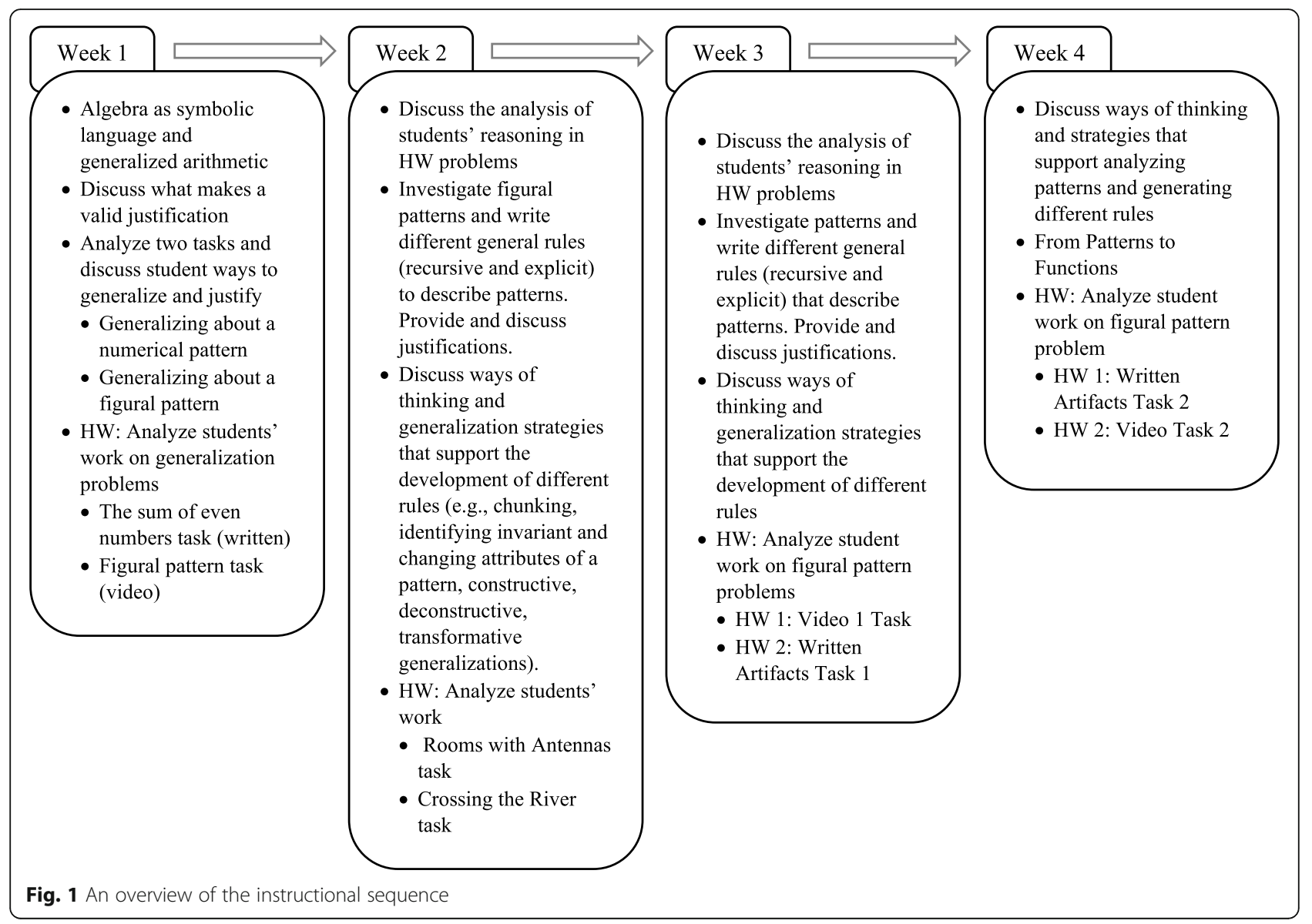

figural patterns. We designed the tasks to highlight different ways of reasoning, a variety of generalization strategies, as well as valid, invalid, or incomplete justifications. Two tasks contained short video clips of students who shared their reasoning in small groups. The other two tasks included students' written work, which we selected to document students' reasoning about figural patterns. We provided PSTs with sufficient time to complete each task. They could revisit student strategies by watching each video clip or examining written artifacts of students' work as many times as they needed to understand and make sense of students' thinking. The tasks (Figs. 2, 3, and 4) were introduced in the following order: video 1 , written artifacts 1 , written artifacts 2 , and video 2. We presented PSTs with our tasks after the initial class sessions during which PSTs engaged in the practice of generalizing and justifying, discussed explicit and recursive generalization strategies and features of valid justifications.

For all tasks, we explicitly asked PSTs to identify mathematically significant aspects of students' reasoning. While we directed PSTs' attention to students' generalizations and justifications, we intentionally used an open prompt without defining the term mathematically significant to avoid leading PSTs to any particular aspect of student generalizations or justifications. We asked PSTs to identify and provide interpretations of mathematically significant aspects of student thinking to assess PSTs' attending-andinterpreting skills. To assess PSTs' responding skills, we explicitly asked them to describe how they would follow up with a student (or a group of students in case of analyzing video-records of small groups) to support students' justification and generalization skills.

We used the available video-library of elementary and middle grades students' mathematical thinking in designing our video tasks. For the first task, we selected short clips of two small groups of students discussing their thinking about the Beam Pattern (selected from http:// mathincontext.eb.com/teacher-resources). For the second task, we selected short clips of two small groups of students discussing their reasoning about the Button Pattern (selected from http://www.insidemathematics.org/classroomvideos/public-lessons/5th-6th-grade-math-multiple-

representations-of-numerical-patterning/problem-1).

Consistent with Leatham, Peterson, Stockero, and Van Zoest (2015), we interpreted observable student actions (e.g., gestures, verbal statements, or written work) as mathematically significant as these actions provided 
Video Task 1: Beam Problem. Observe the number of rods for each Beam Length below. Without drawing and counting the number of rods, can you tell how many rods it would be in the Beam Length 6 ? How would you calculate the total number of rods for any given Beam Length?

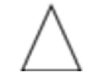

Beam Length 1

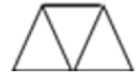

Beam Length 2

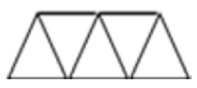

Beam Length 3

A class of seventh grade students worked on the Beam Problem above. Two conjectures about the Beam Problem were developed by two student groups. In their discussion, the students used $L$ to represent the length of the beam.

Group 1: The total number of beams can be found as $4 L-1$

Group 2: The total number of beams can be found as $L+2 L+(L-1)$

1) Watch the provided video-clips showing each group's work. 1) How does each group reason about the Beam Problem? For each group, describe mathematically significant details of students' responses. Comment on justification and generalization skills of students in each group.

2) Imagine having each group of students in your own classroom. How would you respond to the students in each group (what questions or problems would you pose to each group) to support students' justification and generalization skills? Be specific explaining why your proposed responses would support the students in each group.

Video Task 2: Button Problem: Observe the number of buttons for each Pattern number below. Without drawing and counting the number of buttons, can you tell how many buttons it would be in the Pattern 11?

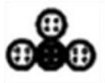

Pattern 1

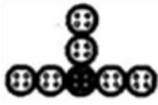

Pattern 2

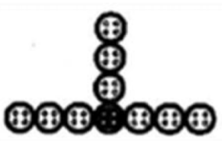

Pattern 3

Learner B' Solution: 34 . I added $4+3+3+3+3+3+3+3+3+3+3=34$, which is the number of buttons.

Watch the provided video-clips showing two groups of students of discussing Learner B's solution to the Button Problem I.

1) Describe how do the students in each group reason about Learner B's solution to the Button Problem? For each group, describe mathematically significant details of students' responses. Comment on justification and generalization skills of students in each group.

2) Imagine having each group of students in your own classroom. How would you respond to the students in each group (what questions or problems would you pose to each group) to support students' justification and generalization skills? Be specific explaining why your proposed responses would support the students in each group.

Fig. 2 Video tasks 1 and 2

evidence for making inferences about ways in which students reasoned to construct generalizations and justifications. We selected clips that depicted how students make sense of patterns by identifying their changing or invariant features, constructing or deconstructing patterns using manipulative materials, generating recursive or explicit rules, and providing reasons to justify their thinking. For the written artifacts tasks, we used the available samples of students' written work that documented similar ways of reasoning. Selected video and written artifacts tasks allowed for identifying different generalization strategies (e.g., counting from a drawing, recursive, identifying repeating chunks, composing and decomposing pattern structure, identifying invariant, and changing pattern characteristics). Both types of tasks provided an opportunity to notice whether students justified their general rules and how. The
Additional file 1 includes a summary of opportunities for noticing that each of the four tasks provided.

\section{Data analysis \\ Phase 1: assessing PSTs' attending-and-interpreting and responding practices}

We first examined PSTs' responses focusing on the attending-and-interpreting and responding components of PSTs' noticing. For the attending-and-interpreting aspect of noticing practice, we considered the extent to which PSTs' explanations demonstrated awareness and evidence of mathematical details of student thinking and how well PSTs were able to explain their observations with attention to students' generalizations and justifications strategies. For the responding practice, we focused on choices of instructional interventions (i.e., ways to follow up with students) PSTs suggested with specific 
Written Artifacts Task 1: Flower Beds. The city council wishes to create 100 flower beds and surround them with hexagonal paving slabs according to the pattern below. (In the pattern below 18 slabs surround 4 flower beds). Without drawing and counting the number of slabs, can you tell how many slabs it would be for 100 flower beds? How would you calculate the total number of slabs for any given number of flower beds?

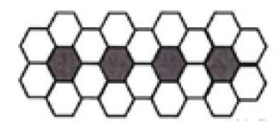

This is how Student A reasoned about the Flower Beds Problem:

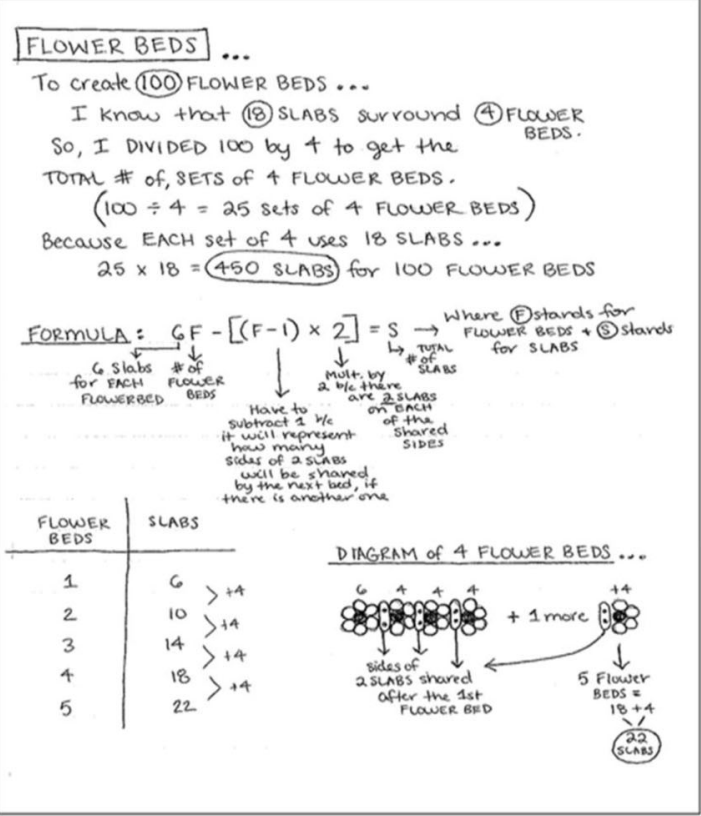

Carefully analyze Student A's work and respond to the following two questions:

1) How does Student A reason about the Flower Beds Problem? Share mathematically significant details evident in Student A's response. What can you say about Student A's justification and generalization skills?

2) Imagine Student A in your own classroom. Propose how you would respond to the student (what questions or problems would you pose) to support Student A's justification and generalization skills? Be specific explaining why you proposed response would support the student.

Fig. 3 Written artifacts task 1 (student work from Magiera, van den Kieboom, \& Moyer, 2017)

attention to how well the proposed choices of instructional follow up addressed aspects of student thinking that PSTs recognized and interpreted. To guide our assessment of PSTs' noticing skills (attending-and-interpreting, and responding), the authors and a trained research assistant developed, tested, and revised as necessary, a rubric for the use with PSTs' responses to all tasks. Our goal was to reliably capture all observations and interpretations that PSTs shared about students' generalizations and justifications (attending-and-interpreting) and strategies they proposed to follow-up on students' ideas (responding).

Scoring rubric: attending-and-interpreting For the attending-and-interpreting component of noticing, we categorized each PST's practice as Highly Focused if the PST addressed mathematically significant aspects of student thinking about pattern generalization and justification and provided their comprehensive interpretation with a focus on generalization and justification strategies. We categorized attending-and-interpreting as Partially Focused if the PST identified mathematically significant aspects of student thinking about pattern generalization and justification but did not provide in-depth interpretation. Finally, we categorized attending-and-interpreting as Superficial if the PST did not recognize any mathematically significant aspects of student thinking about pattern generalization and justification or demonstrated only minimal awareness of student generalization and justifications strategies with incorrect or no interpretation. 
Written Artifacts Task 2: Button Problem. Gina, a seventh-grade student, observes the number of buttons for each Pattern number below. She thinks that she needs 69 buttons in all to make Pattern 24. Is Gina correct or not? How do you know that she is correct or not? Explain.

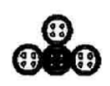

Pattern 1

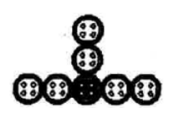

Pattern 2

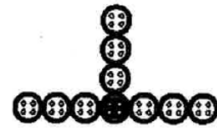

Pattern 3

This is how Learner $\mathrm{C}$ and Learner D reasoned about the Button Problem:

Learner C: $69-3=66 ; 66-30=36 ; 36-30=6$; and 6-6=0. I know we add 3 each time. So, I took $3 \mathrm{~s}$ away until I could not do it anymore. $1+10+10+2=23$. Sixty-nine is the number of buttons for Pattern 23. She can't be correct.

Learner D: $25+25+25=75.75-2=73$. It doesn't equal 69, so it can't be correct.

Carefully analyze Learner C and Learner D's work:

1) How does each learner reason about the Button Problem? For each learner, describe mathematically significant details of his or her response. Comment on justification and generalization skills of Learner $\mathrm{C}$ and Learner D.

2) Imagine Learners $C$ and $D$ in your own classroom. How you would respond to each student (what questions or problems would you pose) to support Learner C and D's justification and generalization skills? Be specific explaining why you proposed response would support each student.

Fig. 4 Written artifacts task 2 (Samples of student work selected

from http://www.insidemathematics.org/assets/common-core-math-tasks/4th\%20grade/buttons.pdf)

To illustrate our coding scheme, we use verbatim excerpts from PSTs' responses to video task 1 (Fig. 2). For this task, PSTs analyzed two video clips that captured how two small groups of students (group 1 and group 2) reasoned about the beam pattern. Students in group 1 constructed the pattern using toothpicks and, while doing so, recognized the repeating chunk of four rods. The students did not explicitly discuss how the chunk of four rods fits the overall pattern structure and how it relates to the rule they proposed, $4 L-1$. At the time of constructing their pattern using manipulative materials, students gestured, explaining the meaning of "minus 1" in their rule. Using beams of various lengths, they tested whether their rule gives the correct number of rods needed for a given beam pattern length. Students in group 2, on the other hand, were very explicit in their discussion and clearly articulated their thinking about the structure of the beam pattern. The students in group 2 decomposed the pattern structure to generate the rule $L+2 L+(L-1)$ and directly drew on their understanding of the pattern structure to justify their rule. In the discussion below, we use excerpts from PSTs' analyses of group 1's thinking to illustrate our rubric.

Highly focused As stated above, students in group 1 did not articulate the meaning of $4 L-1$ with direct links to the pattern structure. Consider the following excerpt from PST B23's analysis of group 1's thinking, which shows that PST B23 addressed and interpreted the meaning of group 1's rule in the context of the problem. PST B23 shared:

Group 1 created the formula 4L-1. They agreed that each L-segment had 4 toothpicks connected to it, except the last L-segment. They reasoned about different mini-groups:

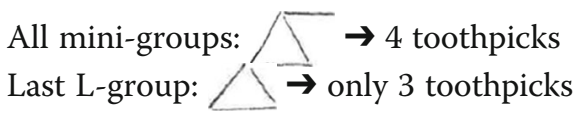

[in group 1's formula] 4L represents each minigroup having the 4 toothpicks. Since the last Lgroup has only 3 toothpicks, which is one less than 4 , group 1 had to subtract 1 . When put together, they got $4 \mathrm{~L}-1$. [PST B23, video task 1, analysis of group 1's thinking, attending-and-interpreting segment]

PST B23 recognized and unpacked group 1's reasoning, making a valid inference about the pattern components that students in group 1 recognized and used to develop their symbolic representation. In her analysis, PST B23 articulated the connections between group 1's rule and the pattern structure. Consistent with our rubric, we scored this attending-and-interpreting segment as Highly Focused (on group 1's generalization/justification strategy). 
Partially focused As an illustration, we use PST B10's response to the same task:

The students [in group 1] began by reasoning that all you had to do to find the number of rods needed was to multiply the beam length by four. However, they then saw that you have to subtract one in order for this idea to work correctly. They drew many examples, such as using $3 \times 4=12$ minus 1 is 11 , and $2 \times 4=8$, minus 1 is seven, which were correct answers. This reasoning had led them to the correct conjecture that to find the number of rods, you can multiply the beam length by four and subtract one. The students had developed sufficient but not strong reasoning for their argument. I believe they are on track to having a deeper understanding of why their conjecture works, but it feels as if they just hit their "ah-ha" moment in the video, meaning they have a good deal of room to now strengthen their argument by providing examples and digging deeper into why it works. [PST B10, video task 1, analysis of group 1's thinking, attending-andinterpreting segment]

PST B10 accurately recognized that group 1 generated multiple numerical examples, which lead them to the $4 \mathrm{~L}-1$ rule. PST B10 also realized that the general conjecture about the total number of rods was correct. Unlike PST B23, however, PST B10 failed to make sense of group 1's rule and interpret student thinking leading to their specific rule. PST B10 did not recognize that the rule $4 \mathrm{~L}-1$ that group 1 developed suggests that the students reasoned about the repeating chunk of 4 rods while constructing the pattern. Instead, PST B10 made a broad observation that group 1 might be "on track to having a deeper understanding of why their conjecture works," without providing any support for his or her assessment of student reasoning. Consistent with our rubric, we assessed PST B10's attending-and-interpreting skills on this problem as Partially Focused.

Superficial Finally, consider an excerpt from PST AB10's response to the same task as an illustration of Superficial attending-and-interpreting:

Group 1 talks about using multiplication. They find that if they only multiply by 4 , they are going over by one beam in length, and then they decide to take out the one. They [Group 1] were working to make connections with operations. [PST AB10, video task 1 , analysis of group 1's thinking, attending-andinterpreting segment]
PST AB10 made very general observations of group 1's reasoning, commenting that the students discussed operations while generalizing the beam pattern. PST AB10 did not attempt to make sense of students' reasoning. She did not make any inferences about what the identified operations suggest about ways in which Group 1 interpreted the pattern and how this interpretation is reflected in the general rule that group 1 developed. PST AB10 stated that group 1 was attempting to make connections with operations but did not explain what these connections were. Consistent with our rubric, we categorized the above segment as representative of Superficial attending-and-interpreting practice.

Scoring rubric: responding For the responding component of noticing, we categorized each PST's practice as Highly Focused if the PST directly linked the suggested way of following up with students to student thinking about pattern generalization and justification. And the strategy they proposed was effective in supporting students in generalizing and justifying. We categorized responding as Partially Focused if the PST proposed a follow-up strategy that directly connected to student thinking, but the proposed strategy was inadequate to effectively support and scaffold student reasoning about pattern generalization and justification. Finally, we categorized responding as Superficial if the PST failed to relate the proposed strategy to student thinking about pattern generalization and justification, or while building on student thinking, the proposed strategy was too vague to support students in generalizing and justifying.

Highly focused We use an excerpt from PST B12's analysis to illustrate this category of responding practice. PST B12 suggested the following interactions with students in Group 1:

I would ask group 1 to find the number for length 31. Both groups would find the same answer, but with a different rule. I would ask two people in each group to switch and have them explain to the other group their reasoning behind their rule. I would have students explain why both ways [rules] work. This will give them a better understanding of how there are multiple ways to find a solution and why the rule works. [PST B12, video task 1, analysis of group 1's thinking, responding segment].

This segment shows that PST B12 recognized and capitalized on her observation that each group reasoned about the beam pattern using different generalization strategies. The proposed response provides an effective scaffold for supporting students' thinking about the beam pattern, connects to broader principles of teaching 
by engaging students in group 1 in considering a different way of reasoning about the pattern, analyzing, and justifying an alternative rule. Consistent with our rubric, we categorized this responding segment as Highly Focused (on supporting students in generalizing and justifying).

Partially focused We illustrate this type of responding practice with an excerpt from PST B16's analysis. PST B16 offered the following suggestion:

For group 1, I would have them try different examples to make sure $4 L-1$ works, but then I would try to get them to see why and how it works. I would ask them if they thought it [the rule] had anything to do with the total \# of triangles. [PST B16, video Task 1, analysis of group 1's thinking, responding segment]

As discussed earlier, group 1 used examples to justify their general rule, 4L-1. While PST B16 addressed students' justifications in her proposed response by suggesting that the students try more examples to ensure the validity of their general rule, the response reinforced the use of example-based justifications. PST B16 did not attempt to move students beyond the example-based justification and draw their attention to the connections between the figure structure and the symbolic rule they developed. That is why we categorized this responding segment as Partially Focused.

Superficial Finally, consider an excerpt from PST AB26's analysis of group 1's thinking:

Teachers should always ask "why" so that students can explain the reasoning for each part of the problem. Pushing the question of 'why' will advance proofs. You can also have them use a diagram to explain their work. [PST AB26, video task 1, analysis of group 1's thinking, responding segment]

Like PST B12 and B16, whose responses we discussed earlier in this section, PST AB26 also intended to engage group 1 in justifying their generalization. However, her instructional suggestion was vague and lacked connections to group 1's thinking. It is unclear how the above response could potentially support students or serve as a scaffold to help them move away from example-based justification to a valid justification for their general rule. Consistent with our rubric, we categorized the presented responding segment as representative of Superficial responding practice.

If the task required PSTs to analyze responses of more than one student or more than one group of students, we separately assessed PSTs' attending-and-interpreting and responding practice for each student (or group of students) they analyzed. Thus, we identified and scored a total of 210 attending-and-interpreting and responding segments: 60 attending-and-interpreting and 60 responding segments for the video ${ }^{1}$ tasks, 45 attendingand-interpreting, and 45 responding segments for the written artifacts tasks.

One of the authors and a trained research assistant independently applied the developed rubric to PSTs' responses. Cohen's $\mathrm{K}$ was computed to determine the level of agreement between the two raters. For the tasks that required PSTs to analyze video-records of students' work, the initial level of agreement was $\mathrm{K}=0.806, p<$ 0.01 ; for the tasks that required PSTs to analyze written artifacts of students' work, the initial level of agreement was $\mathrm{K}=0.919, p<0.01$. Prior to conducting further analyses, the authors and the research assistant negotiated a $100 \%$ agreement on the discrepant cases.

Quantitative analysis We first tabulated frequencies of Highly Focused, Partially Focused, and Superficial attending-and-interpreting and responding segments. To answer our first research question, we conducted the Pearson Chi-square test for association using segments as the unit of analysis. Our goal was to examine a possible relationship between the Nature of Artifacts and the Levels of Attending-and-Interpreting, and the Nature of Artifacts and the Levels of Responding. Chi-square test allows for comparing frequencies of mutually exclusive categories and determining whether two nominal or ordinal variables are associated or not (Gravetter \& Wallnau, 2017; Khusainova, Shilova, \& Curteva, 2016). Our response categories for the three levels of attendingand-interpreting and responding, and the two task categories (written artifacts or video tasks) were mutually exclusive. Using the Chi-square test, we then compared frequencies of Highly Focused, Partially Focused, and Superficial segments representative of attending-andinterpreting and responding practices for both types of tasks. To further delineate any potential differences in the attending-and-interpreting and responding practices between written artifacts and video tasks, we followed with posthoc tests with Bonferroni correction for multiple comparisons (Triola, 2014). We used the Bonferroni correction with $\alpha=\frac{0.05}{3}=0.017$ to compare frequencies of the three levels of attending-and-interpreting between the two types of tasks. We conducted similar pair-wise comparisons for responding.

\footnotetext{
${ }^{1}$ Across our two video tasks, PSTs analyzed the mathematical thinking of 4 small groups of students; across our two written artifacts tasks PSTs analyzed the mathematical thinking of 3 students.
} 
Phase 2: characterizing the nature of PSTs' attending-andinterpreting and responding across the written artifacts and video tasks

Drawing on the existing literature (see the "Generalizing and justifying" section), and using qualitative methods and open coding (Saldaña, 2016), we systematically annotated each attending-and-interpreting and responding segment with an emphasis on specific ideas PSTs addressed. We continued comparing and contrasting segments revising and collapsing their descriptions into emergent codes until we established definitions for the final codes. (Depending on the breath of PSTs' observations of student thinking, a given segment could have more than one code which reflected different ideas addressed). To identify any patterns across the characteristics of PSTs' attending-and-interpreting and responding practices in the context of both types of tasks, we tabulated code frequencies. The analysis revealed six characteristics of attending-and-interpreting and six characteristics of responding practices. In the "Results" section that follows, we present the overall comparison of PSTs' attending-and-interpreting and responding practices in the context of both types of tasks and discuss the identified characteristics of PSTs' noticing of student generalizations and justifications.

\section{Results}

Summarized in Table 1 are the proportions of segments representative of Highly Focused, Partially Focused, and Superficial attending-and-interpreting and responding practices identified across our data.

Pearson Chi-square test showed statistically significant differences among proportions of Highly Focused, Partially Focused, and Superficial attending-and-interpreting segments between written artifacts and video tasks $\chi^{2}(2,105)=11.952, p=0.003$. Posthoc analysis with Bonferroni corrections for multiple comparisons $(\alpha=$ 0.017) revealed that Highly Focused attending-and-interpreting segments were significantly more prevalent within the written artifacts tasks than video tasks $\left(\chi^{2}(1,41)=\right.$ $11.608, p=0.0003)$. The proportions of Partially Focused attending-and interpreting, as well as Superficial attending and interpreting segments, did not significantly differ between the written artifacts and video tasks.

Pearson Chi-square analysis also revealed statistically significant differences in proportions of Highly Focused,
Partially Focused, and Superficial responding segments for the written artifacts and video tasks $\chi^{2}(2,105)=8.497, p=$ 0.014. Posthoc analysis with Bonferroni corrections for multiple comparisons $(\alpha=0.017)$ showed that segments representing Partially Focused Responding were far more frequent within written artifacts tasks than video tasks $\left(x^{2}(1,48)=\right.$ $4.618, p=0.01582)$. The proportion of segments representing Superficial responding was significantly lower across the written artifacts tasks compared to video tasks $\left(x^{2}(1,45)=\right.$ 8.429, $p=0.00185)$. As summarized in Table 1, Highly Focused responding segments were overall infrequent for both types of tasks, and the difference in proportions was not statistically significant. The effect sizes of the observed differences in attending-and-interpreting and responding practices between written artifacts and video tasks were moderate (Cramér's $V=0.337$ for attending-andinterpreting, Cramér's $V=0.284$ for responding).

\section{Features of PSTs' attending-and-interpreting practice}

Across all attending-and-interpreting segments discerned from PSTs' analyses, we identified six characteristics of PSTs' attending-and-interpreting practice. Table 2 shows frequencies of attending-and-interpreting segments across the written artifacts and video tasks with identified characteristics. We further describe each characteristic and illustrate it with data excerpts.

\section{Attending to and interpreting contextual links between students' conjectures and their justifications}

Both types of tasks provided PSTs with an opportunity to think about how students justified their generalizations. That is, whether students connected their generalizations to the pattern's structure, provided empirical justifications, or gave no explicit justifications. As summarized in Table 2 , in their analyses of written artifacts and video tasks alike, many of the PSTs examined and interpreted whether or how students justified their generalizations. The most prevalent focus on justifications was observable in analyses of written artifacts tasks. Overall, $80 \%$ of attending-and-interpreting segments across the written artifacts tasks and $46.7 \%$ of segments across the video tasks included evidence that PSTs recognized and engaged in interpreting justifications of students' conjectures. We illustrate this focus of attending-and-interpreting practice with an excerpt from PST B12's analysis:

Table 1 Summary of attending-and-interpreting and responding practices in the context of video and written artifacts tasks

\begin{tabular}{|c|c|c|c|c|c|c|}
\hline \multirow[t]{2}{*}{ Task type } & \multicolumn{3}{|c|}{ Attending-and-interpreting } & \multicolumn{3}{|l|}{ Responding } \\
\hline & Highly focused & Partially focused & Superficial & Highly focused & Partially focused & Superficial \\
\hline Written artifacts $n^{a}=45$ & $26(57.8 \%)$ & $13(28.9 \%)$ & $6(13.3 \%)$ & $7(15.6 \%)$ & $26(57.8 \%)$ & $12(26.7 \%)$ \\
\hline Video $n^{a}=60$ & $15(25 \%)$ & $27(45 \%)$ & $18(30 \%)$ & $5(8.3 \%)$ & $22(36.7 \%)$ & $33(55 \%)$ \\
\hline
\end{tabular}

${ }^{\mathrm{a}}$ Number of analyzed segments 
Table 2 Features of the attending-and-interpreting practice

\begin{tabular}{|c|c|c|}
\hline \multirow[t]{2}{*}{ Characteristics of attending-and-interpreting practice ${ }^{\mathrm{b}}$} & \multicolumn{2}{|l|}{ Task type } \\
\hline & Written artifacts $\left(n^{\mathrm{a}}=45\right)$ & Video $\left(n^{\mathrm{a}}=60\right)$ \\
\hline Attending to and interpreting contextual links between students' conjectures and their justifications & $36(80 \%)$ & $28(46.7 \%)$ \\
\hline Attending to and interpreting ways in which students make sense of patterns & $10(22.2 \%)$ & $2(3.3 \%)$ \\
\hline Attending to and interpreting student generalization strategies & $13(28.9 \%)$ & $4(6.7 \%)$ \\
\hline Attending to and interpreting non-mathematical aspects of student work & $1(2.2 \%)$ & $12(20 \%)$ \\
\hline Retelling & $8(17.8 \%)$ & $34(56.7 \%)$ \\
\hline Attending to and interpreting one's own understanding of student thinking & $4(8.9 \%)$ & $1(1.7 \%)$ \\
\hline
\end{tabular}

${ }^{a}$ Number of analyzed attending-and-interpreting segments

${ }^{b}$ Each attending-and-interpreting segment could have more than one characteristic. Thus, the sum exceeds $100 \%$

At first, the student approached the problem in a way that resulted in an incorrect answer. Her first response did not account for the shared sides between the groups of 4 [flower beds].

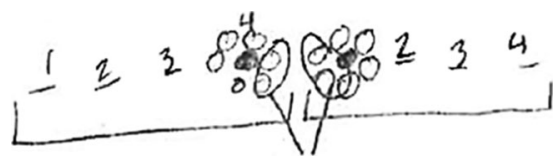

These two [slabs] would be shared because the flower beds are continuous. Then I think she realized this overlap after making a table. She saw the relation between the $4^{\text {th }}$ and $5^{\text {th }}$ [flower bed]. This was further explored in her diagram. The formula is clearly labeled. [PST B12, written artifacts task 1, analysis of student thinking, attending-and-interpreting segment].

Recall that the written artifacts task 1 provided PSTs with the opportunity to identify three strategies (i.e., ways of reasoning) that student A documented in the flower beds problem solution. The first (numerical representation of the flower beds pattern) stemmed from student A's incorrect reasoning about how the pattern works. In the above excerpt, PST B12 addresses this aspect of student thinking and supports her observation of student A's incorrect reasoning and incorrect conclusion. PST B12 draws a diagram that she uses to illustrate that while iterating sets of four flower beds (student A's strategy), student A fails to account for the overlapping two slabs shared by two groups of four flower beds. PST B12 shows her awareness of incorrect reasoning on which the first part of student A's solution rests and provides contextual links to support her observation.

\section{Attending to and interpreting ways in which students make sense of patterns}

Overall, $22.2 \%$ of segments across the written artifacts tasks and $3.3 \%$ of segments across the video tasks included evidence that PSTs analyzed students' reasoning about patterns. PSTs focused on representations students used to document their thinking in these types of segments and examined what these different representations reveal. We illustrate this focus of PSTs' attending-and-interpreting practice with the excerpt below:

As far as the formula goes, the student wrote a correct formula that could be used for this [100 flowerbeds]. However, the formula $4 n+2$ would better represent the first part of the data [what she shows in her table]. The formula $6 F-\{(F-1) \times 2\}=S$ is accurately explained, showing where she gets the parts from, but this formula does not match her earlier thinking, which is represented in her table. [PST B21, Written Artifacts Task 1, Analysis of student thinking, attending-and-interpreting segment].

The excerpt shows that PST B21 noticed different representations included in student A's solution. She examined what these representations reveal about how student A made sense of a given pattern and interpreted inconsistencies between the general rule and student thinking about the pattern exemplified in tabular representation. PST B21 recognized inconsistency between the rule $6 F-[(F-1) \times 2]=S$ and tabular representation included in student A's written solution. PST B21 recognized that thinking about the flower beds pattern documented in student A's table leads to a different rule (i.e., $4 n+2)$, not included in the student's written work.

\section{Attending to and interpreting student generalization strategies}

These types of attending-and-interpreting segments documented that PSTs engaged in thinking about how the student whose work they analyzed reasoned to develop generalization. PSTs addressed students' generalization strategies in $29 \%$ of attending-and-interpreting segments across the written artifacts and $6.7 \%$ of attending-andinterpreting segments across the video tasks. Consider the following excerpt from PST AB29's analysis: 
The student's work shows that they understood how to create a mathematical equation that can be used to solve for any number of flower beds. $6 \mathrm{~F}$ shows that the student realized [that] for each flower bed there are six slabs that surround it. And then, the student realized that two of these slabs are shared and represented that [information] with $-\{(F-1) \times 2\}$. [PST AB29, Written Artifacts Task 1, Analysis of student thinking, attending-andinterpreting segment].

PST AB29 recognized that the student deconstructed the pattern to develop the general rule for the flower beds sequence by first separating the sequence into separate units of flower beds, each requiring $6 \mathrm{~F}$ slabs. Furthermore, she also recognized that the student reasoned about (F-1) repeating chunks of two overlapping slabs compensating for the overlaps in the developed rule. PST AB29 attended to and made sense of the strategy student used to generalize in this problem situation.

\section{Retelling}

This characteristic of attending-and-interpreting practice was identified across $56.7 \%$ of segments discerned from the PSTs' analyses of video tasks and $17.8 \%$ of segments from written artifacts tasks. Retelling segments included narrations of what the student (or a group of students) did without a clear focus on interpreting and making sense of student's generalizations and justifications. Consider the following excerpt, which documents PST AB12's awareness of a group member's actions that directed students' attention to the center of the Button Pattern, and the surrounding repeating chunk:

Group 1 was able to make sense of Learner B's work by asking the question, "I do not understand where the four is coming from?". From that statement on, the other girl was able to explain her reason behind where she thought Learner $B$ got the four. She points with her finger to the image showing the middle button and three surrounding buttons. She then said that the buttons increased by three and pointed to the buttons surrounding the original four. [PST AB12, video task 2, analysis of group 1's thinking, attending-and-interpreting segment].

The moment in the video that PST AB12 describes captures how group 1 unpacked and made sense of learner B's generalization strategy. While PST AB12 recognized this moment, she merely reported what group 1 did, without interpreting students' actions in terms of their thinking and understanding of learner B's generalization strategy.
Attending to and interpreting non-mathematical aspects of student work

Segments with this characteristic represented attendingand-interpreting practice that did not address the mathematical aspects of student work. Twenty percent of segments across the video tasks and 2.2\% of segments across the written artifacts tasks had this characteristic. An excerpt from PST B16 shows her focus on the length of groups' interactions and the overall assessment of students' understanding:

Group 1 took a little longer than group 2 to make sense of Learner B's solution. Group 1 did more analysis: they used words like verbal representation and pattern. On the other hand, group 2 quickly figured out what was going on- three were being added each time. Overall, I think that group 2 talked it through better and understood the patterns better." [PST B16, video task 2, analysis of group 1's thinking, attending-and-interpreting segment].

Even though PST B16 noted groups 2's discussion about the repeating chunk of three buttons, in her task analysis, she did not connect her observation of students' discussion to what this discussion might reveal about students' reasoning and pattern generalization strategy.

\section{Attending to and interpreting one's own understanding of student thinking}

As summarized in Table 2, this category of attendingand-interpreting segments was overall infrequent across our data (identified in $8.9 \%$ of segments across the written artifacts tasks and $1.7 \%$ of segments across the video tasks). Segments with this characteristic documented PSTs' inability to unpack student thinking and strategies. Rather than make sense of student reasoning, PSTs commented on their own lack of understanding of student reasoning. An excerpt from PST B17 serves as an illustration: "I am not sure where Learner $\mathrm{C}$ got $1+10$ $+10+2$ from, and how these are related to her $69-3$ that she was doing" (written artifacts task 2).

\section{Features of PSTs' responding practice}

We also identified six characteristics of PSTs' responding practice, which we summarize in Table 3.

\section{Responding with a focus on contextual justifications of specific mathematical ideas}

Responses focused on clearly articulated mathematical ideas were identified in $73.3 \%$ of segments discerned from analyses of written artifacts tasks, and $41.7 \%$ of segments discerned from PSTs' analyses of video tasks. In those segments, PSTs' aimed to help students justify their rules with links to the overall pattern structure and 
Table 3 Features of the responding practice

\begin{tabular}{lll}
\hline Characteristics of responding practice $^{\mathbf{b}}$ & \multicolumn{1}{l}{ Task type } & Video $\left(\boldsymbol{n}^{\mathbf{a}}=\mathbf{6 0}\right)$ \\
\cline { 2 - 3 } & Written artifacts $\left(\boldsymbol{n}^{\mathbf{a}}=\mathbf{4 5}\right)$ & $25(41.7 \%)$ \\
\hline Responding with focus on contextual justifications of specific ideas & $33(73.3 \%)$ & $7(11.7 \%)$ \\
Unfocused calls for justifications & $1(2.2 \%)$ & $22(36.7 \%)$ \\
Derailing & $4(8.9 \%)$ & $7(11.7 \%)$ \\
Prompting to think about invariant and changing aspects of a pattern & $3(6.7 \%)$ & $6(10 \%)$ \\
Prompting to construct generalizations & $9(20 \%)$ & $9(15 \%)$ \\
Prompting for empirical justifications & $12(26.7 \%)$ & \\
\hline
\end{tabular}

${ }^{a}$ Number of responding segments analyzed

${ }^{b}$ Each responding segment could have more than one characteristic. Thus, the sum exceeds $100 \%$

provide contextual justifications. Consider the following excerpt as an illustration:

I would ask the student [learner D] to explain it [his strategy]. Students are forgetting that there was that one [button] that stayed the same. I would ask Learner D to explain where all the different numbers come from and why he was adding 25 when he was looking for pattern 24. [PST B16, written artifacts task 2, analysis of learner D's thinking, responding segment].

To place PST B16's suggestion in context, consider the associated attending-and-interpreting segment from PST B16's analysis of learner D's thinking:

I see that he [learner D] adds an extra three because he is doing twenty-five, plus twenty-five, plus twenty-five, equals seventy-five, and then subtracts two. I kind of thought that he was doing $\mathrm{N}$ times three plus one, except he was adding extra two that he did not need and taking out two so that he was still accounting for that center black dot. He [learner $\mathrm{D}$ ] is doing $\mathrm{N}$ plus one, plus $\mathrm{N}$ plus one, plus $\mathrm{N}$ plus one, and then subtracts those extra two center buttons. [PST B16, written artifacts task 2, analysis of learner D's thinking, attending-andinterpreting segment].

PST B16 was aware of the student's generalization strategy and recognized that learner D thought about the $24^{\text {th }}$ figure in the sequence as composed of three "arms" of 25 buttons each; by doing so, learner D needed to compensate for the overcount. PST B16 recognized why learner D's strategy generated the correct result for the $24^{\text {th }}$ figure and closely tailored her proposed response to her observation of learner D's thinking. While eliciting the student's justification, PST B16 drew on her observations of learner D's generalization strategy with the intention to bring learner D's attention to the links between this strategy and the structure of the pattern.

\section{Responding with unfocused calls for justifications}

Responding segments with this characteristic largely revealed PSTs' intentions to follow up on students' ideas and reasoning to elicit justifications. However, the proposed responses were too broad and only conveyed PSTs' intentions to direct a student (or a group of students) to provide justifications, without suggesting specific mathematical actions through which PSTs would engage students in generating justifications. PSTs also lacked a focus on identifying specific mathematical strategies or results that required justifications. This characteristic of responding practice was overall infrequent, identified within $11.7 \%$ of responding segments discerned from PSTs' analyses of video tasks and $2.2 \%$ of responding segments within the written artifacts tasks' analyses. We use the segment below to illustrate:

I want group 1 to think of ways to foster not only their learning but to think of ways to help further learner B's thought process to justify. I believe asking why would help develop group 1 a better level of understanding. [PST AB24, video task 2, analysis of group 1's thinking; responding segment].

To provide context for PST AB 24's proposed response, consider presented below related attending-andinterpreting segment:

Group 1 made sense of learner B's solution saying [that] they had the first four buttons constant, but to get to pattern 11, learner B adds on the 3 buttons eleven times, going one on each side eleven times. Group 1 has a good understanding of learner B's interpretation of the task because they have a full understanding of the constant 4. [A student in group 1 is saying] "well I think that he [learner B] counted like 1, 2, 3, 4." And then he did the three, 1, 2, 3, 1, $2,3,1,2,3$." The students [in group 1] saw how he broke down 4, then 3 was added for every new pattern. [PST AB24, video task 2, analysis of group 1's thinking, attending-and-interpreting segment]. 
PST AB24 was aware of the moment in the video in which group 1 acted out learner B's procedure. PST AB24's interpretation of this moment in the video is limited; she reports on the interactions between the students in group 1 (directly citing their comments) without explaining students' actions in terms of their thinking about learner B's procedure. In her proposed response, PST AB 24 intends to bring groups' attention to justification, but the mathematical focus of PST AB24's response is unclear. It is not clear what specific mathematical ideas students in group 1 needed to understand and what aspect of learner B's strategy they should justify.

\section{Derailing}

As a follow-up strategy, some PSTs suggested engaging a student (or a group of students) in thinking about a different activity, task, or topic without offering ways of helping students build on their current ways of thinking. We categorized such responding practices as Derailing. This characteristic of responding was identified in $36.7 \%$ of segments across all video tasks and $8.9 \%$ of segments across all written artifacts tasks.

An excerpt from PST AB10's analysis of group 1's thinking (video task 1) serves as an illustration. As described earlier (see the "Data analysis: Phase 1" section), the students in group 1 justified their rule empirically using several numerical examples. PST AB10 recognized the limitations of group 1's justification. In her proposed response, PST AB10 desired to help group 1 connect the explicit rule they developed to the structure of the beam pattern by suggesting the following question: "Will the answer change if each beam length had a different structure? How do we know that beams won't change?"

While PST AB10 intended to direct group 1's attention to the beam pattern structure to help the students move beyond their empirical justification, the questions she proposed appear to have limited potential to support students in reasoning about contextual links between their rule and the pattern structure. This is because her question, "Will the answer change if each beam length had a different structure?" would likely divert students' attention from thinking about the structure of the beam pattern to thinking about a different pattern(s) or problem situations.

\section{Prompting to think about invariant and changing aspects of a pattern}

Some PSTs focused their responses on directing students' attention to the pattern structure. Specifically, pattern features that remained constant and those that changed from one stage to the next. This characteristic of responding practice was overall infrequent, identified in $6.7 \%$ of responding segments across the written artifacts tasks and $11.7 \%$ of responding segments across the video tasks. For example, one PST suggested:

I would ask students to examine what does the 4 mean because they seem to think that learner B still needs a constant of 1 (" 1 has to be added"). I would ask them if they can show me in the physical pattern [model] the 4 and the 1 . I want them to think if learner B accounts for the black button in any way. If yes, where exactly is the 4 coming from and the 3" [PST B11, video task 2, analysis of group 1's thinking; responding segment].

\section{Prompting to construct generalizations}

This category included responses in which PSTs encouraged students to extend their reasoning and ultimately develop general rules for analyzed patterns. We identified this characteristic in $20 \%$ of responding segments across all written artifacts and 10\% of responding segments across all video tasks. One of the PSTs, for example, wrote:

I would ask learner $C$, where she got the three added each time. She [learner C] would use this method and take three away, three away, three away and she'd be left with that one and would have to take one away from that too. ...I would ask her if she could generalize this [strategy] to any pattern number so she doesn't have to subtract. Keeping subtracting could take a long time to do with bigger numbers. [PST AB5, written artifacts task 2, analysis of learner C's thinking; responding segment]

\section{Prompting for empirical justifications}

Included in this category were responding segments in which PSTs documented their intentions to engage students in generating examples to provide support for generalizations. Prompts for empirical justifications were identified in about $27 \%$ of responding segments across the written artifacts tasks and 15\% of responding segments across the video tasks. One of the PSTs commented on her proposed response, stating: "I would want them [students] to think why their formula is right [correct] and to realize that they should have solved at the end using the formula to make their argument watertight" (PST B16, written artifacts task 1, analysis of student thinking, responding segment). PST B16 promoted empirical justification to make student's justification more robust.

\section{Discussion}

In this study, we examined PSTs' initial noticing skills of student generalizations and justifications in the context of PSTs' analyses of written artifacts and video-records 
of student work. Our data revealed differences in PSTs' noticing skills (attending-and-interpreting, and responding) when considering the nature of tasks PSTs analyzed. Given written artifacts tasks, PSTs were more likely to identify and meaningfully interpret student generalizations and justifications than given video tasks. The proportion of Highly Focused attending-and-interpreting segments was significantly higher in PSTs' analyses of written artifacts tasks than video tasks.

PSTs' responding practice also differed when accounting for the nature of tasks they analyzed. They were more likely to connect their proposed responses to students' thinking about pattern generalization and justification working with written artifacts of student work than video-records. Overall, in both types of tasks, Highly Focused responding was infrequent. However, a significantly more Partially Focused responding segments were present across PSTs' analyses of written artifact tasks than video tasks. PSTs' analyses of written artifacts tasks also included significantly less Superficial responding segments than their video task analyses.

One plausible explanation of our PSTs' greater focus on students' generalization and justification strategies while working with written artifacts of student work might be that analyzing written work required them to be more analytical than analyzing videos. Goldsmith and Seago (2011) described practicing teachers who, like our PSTs, were more attentive to mathematics in student thinking while analyzing student written work than teachers who analyzed video-records. Goldsmith and Seago hypothesized that working with videos puts less burden on teachers. They do not have to unpack the logic of students' solutions because they could hear explanations students share (even though these explanations are not always complete and precise). Videos provide chronological information about the development of student ideas. We think this might also be true for PSTs as they learn to pay attention to students' thinking. Written work might provide a more mathematically focused environment compared to videos of students sharing their mathematical thinking in small groups. Student written work might provide fewer clues about student thinking, requiring PSTs to reconstruct student reasoning for themselves. Trying to understand student reasoning, PSTs then might engage with written artifacts on a much deeper level. Similar to Goldsmith and Seago, we believe that analyzing written work demands that PSTs are more analytical as they reflect on and make sense of student thinking. At least on the surface level, many aspects of the videos might appear more transparent for PSTs. For example, they can directly see how students use gestures and hear what students say. Videos also provide a better sense of the chronological order in which ideas develop. Thus, videos might require fewer efforts to unpack students' thinking, explaining PSTs' higher level of attention to student generalization and justification strategies within the written artifacts tasks compared to video tasks.

On the contrary, it might be that videos are more difficult for PSTs to analyze because to make sense of students' thinking, they have to recognize a system of semiotic representations that collectively, in a complementary way, help to externalize students' mathematical reasoning. PSTs have to identify and make sense of sometimes incomplete verbal statements or gestures that students use to express their mathematical ideas. They have to be able to unpack the collective meaning of these representations in terms of student thinking. Written artifacts might then provide a less obscure environment for PSTs' analyses, which could also explain the differences in PSTs' initial noticing skills of student generalization and justification strategies in the two contexts.

Our qualitative results contribute to accumulating the knowledge of specific aspects of student generalization and justification strategies that PSTs address while analyzing student work. We identified themes that PSTs addressed attending-and-interpreting and responding to student generalizations and justifications. Within PSTs' analyses of written artifacts or video tasks, we uncovered and described six foci of PSTs' noticing practice. Most frequently, PSTs examined contextual links between students' conjectures and these conjectures' justifications. This theme was particularly prevalent in analyses of written artifacts tasks compared to video tasks (88\% vs. 46.7\%). Our PSTs also frequently addressed different representations students used to make sense of patterns and develop general rules. This characteristic of attending-and-interpreting practice was also more frequent across the written artifacts tasks than video tasks $(22.2 \%$ vs. 3.3\%). Characteristics of attending-and-interpreting that were most noticeable in PSTs' analyses of video tasks included retelling (56.7\% for video tasks, and $17.8 \%$ for written artifacts tasks) and focus on nonmathematical aspects of students work (20\% for video tasks, and $2.2 \%$ for written artifacts tasks). The overall high frequency of retelling instances in the context of analyzing videos identified in our data is consistent with observations of PSTs' noticing practices reported in prior research (e.g., Goldsmith \& Seago, 2011; Ulusoy, 2020; Vivanet, Santagata, \& Bonaiuti, 2020). Vivanet et al. (2020) shared that when asked to analyze videos of classroom instruction, novice teachers tend to describe what they observe (i.e., retell) and make superficial remarks not directly related to student thinking. Vivanet and colleagues also reported that novice teachers often lack a critical stance toward their observations and do not offer meaningful suggestions (i.e., responding). 
Across our data, we identified six characteristics of PSTs' responding practices. PSTs placed the greatest mathematical emphasis on supporting students in making contextual justifications of specific mathematical ideas. This focus was evident within $73.3 \%$ of responding segments delineated from PSTs' analyses of written artifacts tasks and $41.7 \%$ of responding segments delineated from their analyses of video tasks. Less prevalent themes characterizing PSTs' responding practice included general, i.e., unfocused on specific mathematical ideas prompts for justifications, prompts for empirical justifications, prompts for constructing general rules, prompts for thinking about invariant and changing pattern characteristics, and prompts that redirected student thinking to new ideas (i.e., Derailing). It is possible that after choosing one mathematical idea for their response, PSTs did not consider any additional aspects of student thinking as they planned their responses. This hypothesis could explain why, in their proposed responses, PSTs directed students to think about constructing general rules or invariant and changing pattern characteristics less frequently than contextual justifications. In their study of secondary school PSTs and feedback they provide to students, Bleiler, Thompson, and Krajčevski (2014) reported that after identifying first, the most noticeable idea in students' work, PSTs often stopped conducting further analyses. Our qualitative results can bring teacher educators' attention to those aspects of student thinking about pattern generalizations and justification that PSTs infrequently addressed in their proposed responses. Teacher educators could help PSTs identify, make sense of, and plan interventions that target aspects of student thinking that PSTs notice less frequently.

\section{Limitations and recommendation for future research}

We recognize that our research results should be interpreted with caution, and we acknowledge the possible limitations of our study. Our results come from a small homogeneous number of participants from one institution in the USA who volunteered for the study. Thus, these results should not be generalized broadly. We uniquely focused on one specific mathematical domain what limits extending our findings to broader mathematical areas. While designing the tasks, we carefully considered equal opportunities for noticing student generalization and justification strategies our tasks afforded. It is possible, however, that some other differences in tasks could also influence the results. For example, in future research, when PSTs analyze student thinking expressed in writing or captured via videorecords, tasks could be matched further, so both the written and video tasks address similar ways of reasoning, e.g., both recursive or both explicit. It is also unknown if the order in which we administered our tasks has had any effects on PSTs' analyses. Further studies with attention to individual differences within PSTs could also contribute to building a more robust understanding of PSTs' noticing in the two contexts (written artifacts and videos).

While we recognize possible limitations, we also believe that we analyzed a sufficient number of attendingand-interpreting and responding segments (210 in total) and that we reliably characterized PSTs' noticing practice focused on students' generalizations and justifications of figural patterns. We also believe that our work provides insights for mathematics teacher educators about considering the task nature (i.e., ways in which student thinking is captured) as they plan activities to support PSTs' professional noticing skills. Future research with more diverse groups of PSTs, a more extensive selection of tasks, an emphasis on a broader range of mathematical activities, a wider selection of representations (e.g., written artifacts, video-representations, observations of student mathematical thinking in classrooms settings) can generate additional insights into PSTs' initial noticing skills.

\section{Conclusion}

Our work extends the growing body of research on PSTs' professional noticing by illustrating how PSTs' attending-and-interpreting and responding practices differ when controlling for ways in which student mathematical thinking is presented (written artifacts or videos). First, our results reveal that PSTs show greater attention to students' mathematical reasoning when analyzing student generalization and justification strategies given written artifacts of student work compared to video records. We identified a significantly higher proportion of Highly Focused attending-and-interpreting segments and a significantly lower proportion of Superficial responding segments in PSTs' analyses of written artifacts tasks compared to video tasks. One potential implication from our work is that interventions focused on helping PSTs learn to notice students' mathematical thinking could be first set in the context of analyzing written artifacts of student thinking to capitalize on PSTs' initial noticing skills. Engaging PSTs in analyzing a more complex and authentic context of classroom situations captured via videos of small groups, and ultimately whole-class interactions, could then be the next steps toward providing further support for PSTs' noticing skills. Such a trajectory of planning sequences of instructional activities for developing PSTs' noticing skills with attention to how students externalize their mathematical thinking (e.g., in writing, orally, gestures) needs to be tested in future research. The plausibility of the proposed trajectory appears to be supported by Superfine and Bragelman (2018). Unlike our study, 
Superfine and Bragelman examined PSTs' noticing skills using only videos. They reported that PSTs learned to notice students' thinking best when videos were selected with attention to their embedded cognitive loads and progressive complexity.

Our work provides information about PSTs' initial noticing skills with attention to how student thinking is represented (i.e., through written artifacts or videorecords). We bring awareness to the need of helping PSTs recognize and make sense of multiple ways in which students express their thinking: verbally, in writing (e.g., symbolic, pictorial), or non-verbally (e.g., gestures, signs). Teacher educators could plan to be intentional as they help PSTs make sense of multiple ways students communicate their mathematical reasoning.

Moreover, our work adds to the growing body of research on PSTs' noticing skills by identifying aspects of student generalization and justification strategies to which PSTs pay attention to and address in their analyses. About $80 \%$ of segments delineated from PSTs' analyses of written artifact tasks, and $47 \%$ of segments delineated from PSTs' analyses of the video tasks documented that PSTs' engaged in thinking about contextual links between students' conjectures and these conjectures justifications. Focus on contextual justifications of specific mathematical ideas was evident in about $73 \%$ of responding segments delineated from PSTs' analyses of written artifacts tasks and $42 \%$ of responding segments delineated from PSTs' analyses of the video tasks. Other mathematical ideas (e.g., ways in which students make sense of patterns, student generalization strategies) identified within PSTs' attending-and-interpreting segments or responding segments (e.g., drawing student attention to invariant and changing aspects of a pattern) were less frequently observed. Our work also generates questions for future research that can help better understand PSTs' noticing skills. In particular, would asking PSTs to communicate their noticing orally instead of in writing reveal any additional information about their noticing skills in relation to the type of task they analyze?

\section{Supplementary Information}

The online version contains supplementary material available at https://doi. org/10.1186/s40594-020-00263-y.

Additional file 1. Task potential for noticing and discussing generalizations and justifications.

\section{Acknowledgements}

The authors would like to express their sincere thank you to the anonymous reviewers for their thoughtful and critical feedback on earlier versions of this article.

\section{Authors' contributions}

MM conceptualized the work, oversaw all aspects of the research, and wrote the manuscript and manuscript revisions. VZ contributed to data analysis and drafted portions of the manuscript. Both authors read and approved the final manuscript.

\section{Funding}

This research was supported by the National Science Foundation's grant to Marta T. Magiera for the project "CAREER: L-MAP: Pre-service Middle School Teachers' Knowledge of Mathematical Argumentation and Proving," Grant No. DRL-1350802. Opinions, findings, conclusions, or recommendations are those of the authors and do not necessarily reflect the views of the National Science Foundation.

\section{Availability of data and materials}

Data for this article are not publicly available because this would violate the terms of our IRB approval.

\section{Competing interests}

The authors declare that they have no competing interests.

\section{Author details}

${ }^{1}$ Department of Mathematical and Statistical Sciences, Marquette University, P.O. Box 1881, 1313 W. Wisconsin Avenue, Milwaukee, WI 53201-1881, USA. ${ }^{2}$ Department of Curriculum and Instruction, Monmouth University, McAllan Hall, Room 209, West Long Branch, NJ 07764, USA.

Received: 23 March 2020 Accepted: 13 December 2020

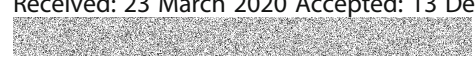

\section{References}

Amador, J. M., Estapa, A., de Araujo, Z., Kosko, K. W., \& Weston, T. L. (2017). Eliciting and analyzing preservice teachers' mathematical noticing. Mathematics Teacher Educator, 5(2), 158-177.

Amit, M., \& Neria, D. (2008). "Rising to the challenge": Using generalization in pattern problems to unearth the algebraic skills of talented pre-algebra students. ZDM, 40(1), 111-129.

Barnhart, S., \& van ES, E. (2015). Studying teacher noticing: Examining the relationship among pre-service science teachers' ability to attend, analyze and respond to student thinking. Teaching and Teacher Education, 45, 83-93.

Bautista, A., Brizuela, B. M., Glennie, C. R., \& Caddle, M. C. (2014). Mathematics teachers attending and responding to students' thinking: Diverse paths across diverse assignments. International Journal for Mathematics Teaching and Learning Retrieved from http://www.cimt.org.uk/journal/.

Becker, J. R., \& Rivera, F. (2005). Generalization schemes in algebra of beginning high school students. In H. Chick, \& J. Vincent (Eds.), Proceedings of the 29th annual conference of the International Group for the Psychology of Mathematics Education (Vol. 4, pp. 121-128). Melbourne: PME.

Blanton, M., \& Kaput, J. (2000). Generalizing and progressively formalizing in a third grade mathematics classroom: Conversations about even and odd numbers. In M. Fernandez (Ed.), Proceedings of the $22^{\text {nd }}$ annual meeting of the North American chapter of the international group for the psychology in mathematics education, (vol. 1, pp. 115-119). Columbus: PMENA.

Bleiler, S. K., Thompson, D. R., \& Krajčevski, M. (2014). Providing written feedback on students' mathematical arguments: Proof validation of prospective secondary mathematics teachers. Journal of Mathematics Teacher Education, $17(2), 105-127$

Callejo, M. L., \& Zapatera, A. (2017). Prospective primary teachers' noticing of students' understanding of pattern generalization. Journal of Mathematics Teacher Education, 20(4), 309-333.

Carpenter, T. P., Fennema, E., Peterson, P. L., Chiang, C. P., \& Loef, M. (1989). Using knowledge of children's mathematics thinking in classroom teaching: An experimental study. American Educational Research Journal, 26(4), 499-531.

Chamberlin, M. T. (2005). Teachers' discussions of students' thinking: Meeting the challenge of attending to students' thinking. Journal of Mathematics Teacher Education, 8(2), 141-170.

Crespo, S. (2000). Seeing more than right and wrong answers: Prospective teachers' interpretations of students' mathematical work. Journal of Mathematics Teacher Education, 3(2), 155-181. 
Ellis, A. B. (2007b). A taxonomy for categorizing generalizations: Generalizing actions and reflective generalizations. The Journal of the Learning Sciences, 16(2), 221-262

Ellis, E. (2007a). Connections between generalizing and justifying: Students' reasoning with linear relationships. Journal for Research in Mathematics Education, 38(3), 194-229.

English, L., \& Warren, E. (1998). General reasoning processes and elementary algebraic understanding: Implications for instruction. Focus on Learning Problems in Mathematics, 17(4), 1-19.

Fernández, C., Llinares, S., \& Valls, J. (2013). Primary school teacher's noticing of students' mathematical thinking in problem solving. The Mathematics Enthusiast, 10(1/2), 441-467.

Goldsmith, L. T., \& Seago, N. (2011). Using classroom artifacts to focus teachers' noticing. In M. G. Sherin, V. R. Jacobs, \& R. A. Philipp (Eds.), Mathematics teacher noticing: Seeing through teachers' eyes, (pp. 169-187). New York: Routledge.

González, G., \& Skultety, L. (2018). Teacher learning in a combined professional development intervention. Teaching and Teacher Education, 71, 341-354.

Gravetter, F. J., \& Wallnau, L. B. (2017). Statistics for the behavioral sciences, (10th ed., ). Boston: Cengage Learning.

Jacobs, V. R., Lamb, L. L., \& Philipp, R. A. (2010). Professional noticing of children's mathematical thinking. Journal for Research in Mathematics Education, 41(2), 169-202.

Jacobs, V. R., Lamb, L. L., Philipp, R. A., \& Schappelle, B. P. (2011). Deciding how to respond on the basis of children's understanding. In M. G. Sherin, V. R. Jacobs, \& R. A. Philipp (Eds.), Mathematics teacher noticing: Seeing through teachers' eyes, (pp. 97-116). New York: Routledge.

Jilk, L. M. (2016). Supporting teacher noticing of students' mathematical strengths. Mathematics Teacher Educator, 4(2), 188-199.

Khusainova, R., Shilova, Z., \& Curteva, O. (2016). Selection of appropriate statistical methods for research results processing. Mathematics Education, 11(1), 303-315.

Kleinknecht, M., \& Gröschner, A. (2016). Fostering preservice teachers' noticing with structured video feedback: Results of an online-and video-based intervention study. Teaching and Teacher Education, 59, 45-56.

Knuth, E. J., Choppin, J., Slaughter, M., \& Sutherland, J. (2002). Mapping the conceptual terrain of middle school students' competencies in justifying and proving. In D. S. Mewborn, P. Sztajn, D. Y. White, H. G. Weigel, R. L. Bryant, \& K. Nooney (Eds.), Proceedings of the 24th annual meeting for the psychology of mathematics education - North America, (vol. 4, pp. 1693-1700). Athens: Clearinghouse for Science, Mathematics, and Environmental Education.

Krebs, A. (2005). Studying students' reasoning in writing generalizations. Mathematics Teaching in the Middle School, 10(6), 284-287.

Krupa, E., Huey, M., Lesseig, K., Casey, S., \& Monson, D. (2017). Investigating secondary preservice teacher noticing of students' mathematical thinking. In E. O. Schack, M. H. Fisher, \& J. Wilhelm (Eds.), Teacher noticing - Bridging and broadening perspectives, contexts, and frameworks, (pp. 49-72). New York: Springer https://link.springer.com/chapter/10.1007/978-3-319-46753-5_4.

Lannin, J., Barker, D., \& Townsend, B. (2006). Algebraic generalization strategies: Factors influencing student strategy selection. Mathematics Education Research Journal, 18(3), 3-28.

Lannin, J. K. (2005). Generalization and justification: The challenge of introducing algebraic reasoning through patterning activities. Mathematical Thinking and Learning, 7(3), 231-258.

LaRochelle, R., Nickerson, S., Lamb, L., Hawthorn, C., Phillip, R., \& Ross, D. (2019). Secondary practicing teachers' professional noticing of students' thinking about pattern generalization. Mathematics Teacher Education and Development, 21(1), 4-27.

Leatham, K. R., Peterson, B. E., Stockero, S. L., \& Van Zoest, L. R. (2015) Conceptualizing mathematically significant pedagogical opportunities to build on student thinking. Journal for Research in Mathematics Education, 46, 88-124.

Lee, L. (1996). An initiation into algebraic culture through generalization activities. In N. Bednarz, C. Kieran, \& L. Lee (Eds.), Approaches to algebra: Perspectives for research and teaching, (pp. 87-106). Dordrecht: Kluwer Academic Publishers.

Lee, M. Y. (2018). Further investigation into the quality of teachers' noticing expertise: A proposed framework for evaluating teachers' models of students' mathematical thinking. Eurasia Journal of Mathematics, Science and Technology Education, 14(11), 1-15.

Lee, M. Y., \& Choy, B. (2017). Mathematical teacher noticing: The key to learning from lesson study. In E. O. Schack, J. Wilhelm, \& M. H. Fisher (Eds.), Teacher noticing: Bridging and broadening perspectives, contexts, and frameworks, (pp. 121-140). New York: Springer. https://doi.org/10.1007/978-3-319-46753-5_8.
Llinares, S. (2013). Professional noticing: A component of the mathematics teacher's professional practice. Sisyphus-Journal of Education, 1(3), 76-93.

Luna, M. J. (2018). What does it mean to notice my students' ideas in science today: An investigation of elementary teachers' practice of noticing their students' thinking in science. Cognition and Instruction, 36, 297-329. https:// doi.org/10.1080/07370008.2018.1496919.

Luna, M. J., Selmer, S., \& Rye, J. (2018). Teachers' noticing of students' thinking in science through classroom artifacts: In what ways are science and engineering practices evident? Journal of Science Teacher Education, 29(2), 148-172. https://doi.org/10.1080/1046560X.2018.1427418.

Magiera, M. T., van den Kieboom, L., \& Moyer, J. (2017). K-8 pre-service teachers' algebraic thinking: Exploring the habit of mind building rules to represent functions. Mathematics Teachers Education and Development, 19(2), 25-50.

Mason, J. (1996). Expressing generality and roots to algebra. In N. Bednarz, C. Kieran, \& L. Lee (Eds.), Approaches to algebra: Perspectives for research and teaching, (pp. 65-86). Dordrecht: Kluwer Academic Publishing.

Mason, J. (2002). Researching your own practice: The discipline of noticing. London: Routledge.

Melhuish, K., Thanheiser, E., Fasteen, J., \& Fredericks, J. (2015). Teacher noticing of justification: Attending to the complexity of mathematical content and practice. In T. Bartell, K. Bieda, R. T. Putnam, K. Bradfield, \& H. Dominquez (Eds.), Proceedings of the $37^{\text {th }}$ annual meeting of the North American chapter of the international group for the psychology of mathematics education, (pp. 748755). East Lansing: Michigan State University.

Melhuish, K., Thanheiser, E., \& Guyot, L. (2020). Elementary school teachers' noticing of essential mathematical reasoning forms: Justification and generalization. Journal of Mathematics Teacher Education, 23(1), 35-67. https://doi.org/10.1007/s10857-018-9408-4.

Mouhayar, R. E., \& Jurdak, M. E. (2013). Teachers' ability to identify and explain students' actions in near and far figural pattern generalization tasks. Educational Studies in Mathematics, 82, 379-396.

Philipp, R., Fredenberg, M., \& Hawthorn, C. (2017). Examining student thinking thought teacher noticing: Commentary. In E. O. Schack, M. H. Fisher, \& J. A. Williams (Eds.), Teacher noticing: Bridging and broadening perspectives, contexts, and frameworks, (pp. 113-120). Cham: Springer International Publishing.

Prediger, S., \& Zindel, C. (2017). Deepening prospective mathematics teachers' diagnostic judgments: Interplay of videos, focus questions and didactic categories. European Journal of Science and Mathematics Education, 5(3), 222-242.

Radford, L. (2008). Iconicity and construction: A semiotic investigation of forms of algebraic generalizations of patterns in different contexts. ZDM, 40, 83-96.

Rivera, F. D. (2010). Visual templates in pattern generalization activity. Educational Studies in Mathematics, 73, 297-328.

Rivera, F. D. (2018). Pattern generalization processing of elementary students: Cognitive factors affecting the development of exact mathematical structures. Eurasia Journal of Mathematics, Science and Technology Education, 14(9), 1-31.

Rivera, F. D., \& Becker, J. R. (2007). Abduction-induction (generalization) processes of elementary majors on figural patterns in algebra. The Journal of Mathematical Behavior, 26(2), 140-155.

Rivera, F. D., \& Becker, J. R. (2009). Algebraic reasoning through patterns. Mathematics Teaching in the Middle School, 15(4), 212-221.

Russel, S. J., Schifter, D., \& Bastable, V. (2011). Developing algebraic thinking in the context of arithmetic. In J. Cai, \& E. Knuth (Eds.), Early algebraization: A global dialogue from multiple perspectives, (pp. 43-69). Berlin: Springer-Verlag.

Saldaña, J. (2016). The coding manual for qualitative researchers. Thousand Oaks: Sage Publications Inc

Santagata, R., Zannoni, C., \& Stigler, J. W. (2007). The role of lesson analysis in preservice teacher education: An empirical investigation of teacher learning from a virtual video-based field experience. Journal of Mathematics Teacher Education, 10(2), 123-140.

Schack, E. O., Fisher, M. H., Thomas, J. N., Eisenhardt, S., Tassell, J., \& Yoder, M. (2013). Prospective elementary school teachers' professional noticing of children's early numeracy. Journal of Mathematics Teacher Education, 16(5), 379-397.

Sherin, M. G., \& Han, S. Y. (2004). Teacher learning in the context of video club. Teaching and Teacher Education, 20(2), 163-183.

Sherin, M. G., Jacobs, V. R., \& Philipp, R. A. (Eds.) (2011). Mathematics teacher noticing: Seeing through teachers' eyes. New York: Routledge.

Sherin, M. G., \& van Es, E. A. (2005). Using video to support teachers' ability to notice classroom interactions. Journal of Technology and Teacher Education, 13(3), 475-491. 
Sherin, M. G., \& van Es, E. A. (2009). Effects of video club participation on teachers' professional vision. Journal of Teacher Education, 60(1), 20-37.

Simpson, A., \& Haltiwanger, L. (2017). "This is the first time I've done this": Exploring secondary prospective mathematics teachers' noticing of students' mathematical thinking. Journal of Mathematics Teacher Education, 20(4), 335-355.

Star, J. R., \& Strickland, S. K. (2008). Learning to observe: Using video to improve preservice mathematics teachers' ability to notice. Journal of Mathematics Teacher Education, 11(2), 107-125.

Stockero, S. L., Rupnow, R. L., \& Pascoe, A. E. (2017). Learning to notice important student mathematical thinking in complex classroom interactions. Teaching and Teacher Education, 63, 384-395.

Sun, J., \& van Es, E. A. (2015). An exploratory study of the influence that analyzing teaching has on preservice teachers' classroom practice. Journal of Teacher Education, 66(3), 201-214.

Superfine, A., \& Bragelman, J. (2018). Analyzing the impact of video representation complexity on pre-service teacher noting of children's thinking. Eurasia Journal of Mathematics, Science, and Technology Education, 14(11), 1-18. https://doi.org/10.29333/ejmste/99501.

Teuscher, D., Leatham, K. R., \& Peterson, B. E. (2017). From a framework to a lens: Learning to notice student mathematical thinking. In E. O. Schack, M. H. Fisher, \& J. A. Williams (Eds.), Teacher noticing: Bridging and broadening perspectives, contexts, and frameworks, (pp. 31-48). Cham: Springer International Publishing.

Triola, M. F. (2014). Elementary statistics, (12th ed., ). Boston: Pearson Education.

Ulusoy, F. (2020). Prospective teachers' skills of attending, interpreting, and responding to content-specific characteristics of mathematics instruction in classroom videos. Teaching and Teacher Education, 94, 1-13. https://doi.org/ 10.1016/j.tate.2020.103103.

van den Kieboom, L., Magiera, M. T., \& Moyer, J. (2017). Learning to notice student thinking about the equal sign: K-8 pre-service teachers' experiences in a teacher preparation program. In E. O. Schack, M. H. Fisher, \& J. Wilhelm (Eds.), Teacher noticing - Bridging and broadening perspectives, contexts, and frameworks, (pp. 141-159). New York: Springer https://link.springer.com/ chapter/10.1007\%2F978-3-319-46753-5_9.

van Es, E. A. (2011). A framework for learning to notice student thinking. In M. G. Sherin, V. R. Jacobs, \& R. A. Philipp (Eds.), Mathematics teacher noticing: Seeing through teachers' eyes, (pp. 134-151). New York: Routledge.

van Es, E. A., \& Sherin, M. G. (2002). Learning to notice: Scaffolding new teachers' interpretations of classroom interactions. Journal of Technology and Teacher Education, 10(4), 571-596.

van Es, E. A., \& Sherin, M. G. (2008). Mathematics teachers' "learning to notice" in the context of a video club. Teaching and Teacher Education, 24(2), 244-276.

Vivanet, G., Santagata, R., \& Bonaiuti, G. (2020). Using video to examine teacher noticing and the role of teaching experience. Italian Journal of Educational Technology. https://doi.org/10.17471/2499-4324/1163.

Yerushalmy, M. (1993). Generalization, induction, and conjecturing: A theoretical perspective. In L. Schwartz, M. Yerushalmy, \& B. Wilson (Eds.), The geometric suppose: What is it a case of? (pp. 57-84). Hillsdale: Lawrence Erlbaum.

Zambak, V. S., \& Magiera, M. T. (2018). Pre-service K-8 teachers' professional noticing and strategy evaluation skills: An exploratory study. Eurasia Journal of Mathematics, Science and Technology Education, 14(11), 1-19.

\section{Publisher's Note}

Springer Nature remains neutral with regard to jurisdictional claims in published maps and institutional affiliations.

\section{Submit your manuscript to a SpringerOpen ${ }^{\circ}$ journal and benefit from:}

- Convenient online submission

- Rigorous peer review

- Open access: articles freely available online

- High visibility within the field

- Retaining the copyright to your article

Submit your next manuscript at $\boldsymbol{\nabla}$ springeropen.com 